\title{
The Queering Eye: emplazamientos y enunciaciones de las sexualidades alternas en el manga, anime y fan service
}

\section{The Queering Eye: locations and enunciations of alternative sexualities in manga, anime and fan service}

\author{
Axel Castellanos \\ Investigador independiente - CCD, Guadalajara, \\ México (Maestría en Narrativa Gráfica)
}

\begin{abstract}
Axel Castellanos es licenciado en Comunicación con especialidad en medios audiovisuales y producción gráfica. Maestrante en Narrativa Gráfica, primer programa en México y Latinoamérica y miembro dibujante del colectivo La Patográfica y la revista de tiras cómicas homónima. Posee estudios en la gráfica, la literatura, la cultura pop y las industrias creativas por el Tecnológico de Monterrey y el Centro de Estudios Culturales Roland Barthes con áreas de especialidad en la literatura clásica, el culturalismo, postestructuralismo y estudios queer para la representación de género.
\end{abstract}

Ha publicado monografías sobre cómic, manga, animación e industrias creativas en Razón y Palabra, Telón de Fondo y Argus- $A$ revistas orientadas al análisis y crítica de diferentes formas de arte, lo escenográfico y lo gráfico, desde una visión académica que además alimenta un blog personal editorial sobre lo nuevo de la novela gráfica en el mundo. En el limbo entre lo académico y lo creativo: investigador del cómic desde un coloquio con las perspectivas culturales y a la vez autor del mismo como reflexiones personales y enunciaciones de ficción aprendiendo todavía sobre los procesos de imprenta y distribución.

Fecha de recepción: 31 de enero de 2019

Fecha de aceptación definitiva: 3 de noviembre de 2019 


\title{
Resumen
}

Se exploran los motivos visuales del manga y anime conocidos usualmente como fan service: el uso de representaciones eróticas para deleite de la audiencia. Se enuncian los elementos comunes que construyen las representaciones de estas imágenes eróticas y cómo estas se hacen comúnmente desde una mirada heteronormativa, poniendo en evidencia la concepción binaria de los roles de género y la figura de la mujer sumisa y el hombre dominante. Asimismo, se exploran las formas en que los productos subversivos alienan este punto de enunciación desde la mirada masculina para generar nuevas perspectivas políticas queer.

Palabras clave: erotismo, estudios visuales, fan service, género, hentai, manga, queer, semiótica.

\begin{abstract}
We explore the regular visual motifs in japanese manga and anime, commonly known as fan service: the use of erotic representations for the audience's pleasure. We state the common elements that build the representation of these erotic images and how they are placed from the heterosexual male gaze, remarking the binary gender roles of the fragile woman and the dominant male. Also, we explore the ways in which subversive representations alienate the norm in order to produce (or queerify) the male gaze to generate new political representations of gender and sexuality.
\end{abstract}

Keywords: erotism, fan service, gender, hentai, manga, queer, semiotics, visual studies

\section{Cita bibliográfica}

Castellanos, A. «The Queering Eye: emplazamientos y enunciaciones de las sexualidades alternas en el manga, anime y fan service», en CuCo, Cuadernos de cómic, n. ${ }^{\circ} 13$ (2019), pp. 55-78. 
El manga y anime son quizá los productos culturales de origen japonés más conocidos en el mundo, con un amplio consumo entre entusiastas de amplios espectros demográficos y que han llegado a producir subculturas propias vía una «japonización» del arte y su apreciación, en una lisonja cultural descrita por Jules Claretie en su crónica del Arte Francés de $1872 .{ }^{1}$ Si bien estas manifestaciones culturales ya son exportaciones comunes al mundo y han sido apropiadas por Occidente, la visión purista del consumidor fanático ha resignificado la nomenclatura nipona como una especie de denominación de origen; es decir, si bien tanto las palabras «manga» como «anime» son las exposiciones lingüísticas para referirse al medio del cómic y la animación en Japón, sin una verdadera carga de discurso nacionalista, para el resto del mundo estos términos definen específica y exclusivamente a estos productos creados por y en Japón.

La creación de este claustro entusiasta genera una subcultura anclada en el fanatismo de estos productos culturales japoneses, como diría Beriain: «una ruta para la materialización de símbolos que son vehículos imprescindibles para la conversión de los objetos materiales en bienes simbólicos», ${ }^{2}$ como base para generar una nueva forma de identidad nominativa que, así como el uso de los vocablos, también se etiqueta bajo otro término originario del japonés: el otaku.

Matt Hills hace la aclaración pertinente en su estudio transcultural del fenómeno otaku, donde pone en evidencia que el uso del término es diferente en Japón y en Occidente. Para los fans occidentales el autodenominarse otaku es una expresión de orgullo de identidad como parte de la cultura entusiasta del arte japonés contemporáneo, pero en Japón: «[they] think of otaku the same way most people think of nerds and socially inept». ${ }^{3}$

Esta visibilidad del otro bajo una visión de otredad marginal es esencialmente un motor creativo para la generación de estructuras lingüísticas que formulan códigos y

${ }^{1}$ Claretie, J. L'Art Francaise, en L'art et les Artist Francais, Ed. BilboBazaar (1872).

2 Beriain, J. «Imaginario social, politeísmo y modernidades múltiples», en Revista Anthropos, Universidad de Navarra, enero-marzo de 2003, p. 2. Citado en Bogarín, M. J. «El sustrato teórico del fenómeno otaku», en Revista Observaciones Filosóficas, n. ${ }^{\circ} 6$ (2008). Disponible en https://www. observacionesfilosoficas.net/elsustratoteorico.html

${ }^{3}$ Hills, M. «Transcultural otaku: Japanese representations of fandom and representations of Japan in anime/manga fan cultures», p. 1 (2002). Disponible en https://pdfs.semanticscholar.org/ d62f/f6eb6025b29ab22dddf60ee0bfbf5bea2bda.pdf? ga=2.38970211.1583092000.1572795111$\underline{98359923.1572795111}$ 
lenguajes propios de esta identidad, los cuales son identificables y serán gran parte de nuestro presente análisis.

$\mathrm{El}$ otaku, otro y diferenciable, desde su condición de actor de consumo conforma «un imaginario: una colección de visiones que facultan al usuario para apropiarse de un producto determinado como vehículo para decodificar a la cultura [...] y lograr un control más constante sobre su identidad», ${ }^{4} \mathrm{y}$ con ello deviene un lenguaje con sus códigos culturales que le son identificables y que configuran no solo los anclajes simbólicos de la identidad otaku, sino otros elementos importantes como la producción del deseo erótico y los modos de consumo visual.

Abordaremos el análisis de las manifestaciones de corte erótico y pornográfico dentro de las producciones del manga y anime y su influencia en el mercado global, e intentaremos esbozar una genealogía de los elementos clave para generar este tipo de contenido; viendo el erotismo como un lenguaje, analizaremos sus elementos gramaticales. Además, veremos la mirada de consumo como un ejercicio discursivo con base en producciones desde un poder reticular: la mirada del espectador será no solo la acción lectora automática del producto, sino el primer paso en la construcción nominal de un discurso hegemónico sobre el consumo y configuración del cuerpo y placer.

Bajo esta misma línea, revisaremos manifestaciones culturales atípicas que presentan configuraciones subversivas a la mirada hegemónica y que configuran el consumo del cuerpo y el erotismo desde una perspectiva periférica, en rechazo, desafío o simple alteridad a la normativa de la producción erótica. En el análisis de estos productos usaremos las premisas postestructuralistas de la representación de género, principalmente bajo las ideas de Foucault y Butler, aplicadas a las nuevas configuraciones del cuerpo y performatividades periféricas, de forma que son estos productos generadores de una mirada queer.

Si bien la base del consumo principal son las producciones institucionalizadas lanzadas por los estudios y editoriales establecidos y exportados al mundo, es decir, la producción «legal», revisaremos en profundidad además las producciones generadas por y para fans ya que, al contrario que la industria del cómic occidental, las industrias creativas de Japón tienen una relación más simbiótica con la producción de los fans y utilizan estos medios «no oficiales» dentro de su estructura de promoción y distribución. ${ }^{5}$

Así, la producción hecha por fans se encuentra en realidad dentro del ecosistema transmediático del manga, y ha logrado una convergencia entre lo corporativo y lo

\footnotetext{
${ }^{4}$ Bogarín, M. J. Op. cit.

${ }^{5}$ Hemmann, K. «Queering the media mix: The female gaze in Japanese fan comics», en Transformative Works and Cultures, n. ${ }^{\circ} 20$ (2015). Disponible en https://journal.transformativeworks.org/index. $\mathrm{php} / \mathrm{twc} / \mathrm{article} /$ download/628/540?inline $=1$
} 
autogestivo en un modelo de producción que «must be understood as both top-down corporate-driven process and a bottom-up consumer-driven process». ${ }^{6} \mathrm{El}$ fan entonces tiene un rol más enfático en la producción cultural, en una relación de retroalimentación esencial que altera los procesos creativos de producción, generando un entorno de «inteligencia colectiva», según lo describiría Pierre Levy: «people from diverse backgrounds pool knowledge, debate interpretations and organize through the production of meaning». ${ }^{7}$ Por esta razón la producción del fan, legal o ilegal, debe ser un elemento presente en el análisis de la configuración de la producción cultural erótica y su consumo, ya que ceñirse solo a las producciones institucionalizadas sería dejar de lado un universo de mensajes que reflejan y modifican activamente los discursos hegemónicos.

\section{Fan service: la producción por y para fan}

Llamamos fan service a la inserción de motivos visuales diseñados específicamente para «dar gusto» a los fanáticos de un producto cultural y, si bien este puede ser desde largas secuencias animadas hasta la inclusión de momentos icónicos, la concepción más común de este fenómeno es de carácter sexual y erótico.

En el manga es un fenómeno cotidiano y ampliamente aceptado tanto por autores como por la audiencia como un recurso hasta obligado. Más allá de su papel dramático o ausencia de este, el fan service puede convertirse en un recurso económico que propicia la venta y distribución del producto a través del deleite visual, más que el trabajo narrativo. ${ }^{8}$

El fan service se encuentra institucionalizado y se inserta dentro de una producción oficial editorial; aun así, la producción del fan service también existe fuera de las instituciones comerciales por parte de los mismos entusiastas que buscan ofrecer a sus pares aquellas líneas argumentales, romances o desenlaces que las historias no les dan de manera canónica. La capacidad de producción del fan service ha llevado incluso a nuevas estructuras de producción del manga y anime, generando clasificaciones como el doujinshi: mangas creados por aficionados sobre historias y personajes de otro autor $^{9}$ o propias que han logrado penetrar en el ecosistema de distribución del universo del cómic en Japón.

${ }^{6}$ Deuce, M. y Jenkins, H. «Editorial. Convergence Culture», en The International Journal of Research into New Media Technologies, vol. 14 (1) (2008), p. 6. Disponible en https://journals.sagepub.com/ doi/pdf/10.1177/1354856507084415

7 Citado en Idem, p. 6.

8 Kincaid, C. «Undressing anime fan service», en Japan Powered (1 de diciembre de 2008). Disponible en https://www.japanpowered.com/anime-articles/undressing-anime-fan-service

9 Hemmann, K. Op. cit. 
El doujinshi es, esencialmente, una publicación alternativa a las historias principales creadas de manera independiente y sin el permiso legal de los autores originales, pero que sí llega a producirse en masa y a distribuirse desde editoriales alternativas. Si bien es evidente la violación de los derechos de autor que presenta un medio como este, Kinsella afirma que la industria del cómic japonés es más laxa en cuanto a su acercamiento a las producciones de fans y las ha llegado a integrar dentro de sus cadenas de producción. Estas prácticas han llevado a un crecimiento de la industria ${ }^{10}$ donde el doujinshi muchas veces funciona o como puerta de entrada para nuevos lectores o como vías alternas, casi en universos transmediáticos líquidos donde, si bien están «fuera de la ley», pueden ser argumentos complementarios para lo que las historias canónicas no pueden ofrecer.

Gracias a la proliferación del doujinshi en Japón, la producción creada por fans ha ayudado a generar nuevas narrativas que no están sujetas a la censura del entorno editorial y que han sido un escenario fértil para la gestación de discursos subversivos que desafien, en una primera instancia, la realidad canónica del producto del que parte originalmente la historia derivada, como también a las macronarrativas sociales normativas, en pro de presentar una visión plural del mundo simplemente por el corto espectro de representaciones periféricas bajo la censura editorial.

Sin embargo, la construcción política de la mirada a través del fan service, especialmente de carácter erótico, sigue respondiendo principalmente a un discurso heteronormativo ${ }^{11}$ que refleja la mirada erótica y el deleite del hombre heterosexual, quizá no activamente suprimiendo otras formas de sexualidad, pero sí imponiendo un discurso dominante que se normaliza hasta volverse el parámetro de la representación «normal». ${ }^{2}$

Revisaremos cómo se construyen las miradas subversivas dentro de los motivos visuales del fan service para generar una representación de lo queer a través de la estructuración de la gramática visual que aliena la normativa sexual de la mirada heterocéntrica, para construir nuevos modos de erotismo y deleite. Esto soportado desde las visiones teóricas de Barthes, quien considera que el proceso de significación se da a través de la creación de mitos como unidades culturales complejas, y entendidos estos como la unión y relación de signos en un nuevo discurso, que llevaría a la representación. También se abordarán las posturas de Butler sobre la performatividad queer y la politización del cuerpo a través de una mirada subversiva ante las sexualidades heteronormativas.

${ }_{10}$ Citado en Hemmann, K. Op. cit.

11 Bogarín, M. J. «Kawaii y la cosificación de la mujer en el manga-anime», en Escaner cultural (1 de febrero de 2009). Disponible en http://revista.escaner.cl/node/1157

12 McLelland, M. «A Short History of 'Hentai'», en Intersections: Gender, History and Culture in the Asian Context n. 12 (enero de 2006). Disponible en http://intersections.anu.edu.au/issue12/ mclelland.html 


\section{Entre la ilegalidad y lo transmediático: fan sub y scanlation}

La otra cara de las producciones de fans es el fenómeno del fan sub y la scanlation. A diferencia del doujinshi, que posee toda una estructura de promoción que lo soporta, el fan sub y las scanlation sí son producciones clandestinas cuyo principal objetivo no es la expansión del universo narrativo, sino el acceso a los productos culturales pese al lenguaje y el alcance de la distribución. El fan sub es la traducción a través de subtítulos de un producto de anime que usualmente no se encuentra en el idioma original. La scanlation es también un proceso de traducción de un manga hecho por fans y que no está avalado por quien posee los derechos de las obras. En ambos casos, estas actividades son violaciones claras de las leyes de protección de derechos de autor $\mathrm{y}$, recientemente, Japón ha acentuado sus esfuerzos por combatirlas.

Estas producciones de fans están íntimamente ligadas a la cultura otaku, ya que requiere complejos procesos de codificación cultural. En el caso de la scanlation, el proceso requiere la obtención del material original en japonés para ser digitalizado y luego modificado con un procesador de imágenes para reemplazar el texto por el idioma objetivo. Por lo tanto, el esfuerzo de los grupos que se dedican a esta práctica requieren no solo un acceso a medios legales impresos, sino también conocimiento del idioma, la cultura y los gramemas comunes del cómic.

El proceso de scanlation, mencionan Hubert, Douglas y Manovich en su análisis cuantitativo, es más que solo una mezcla de medios: «Scanlations are neither "remediations" (Jay David Bolter and Richard Grusin) nor 'transmedia' (Henry Jenkins) $[\ldots]$ most writting has considered scanlation either as a subculture or as a market». ${ }^{13}$ Estos esfuerzos son llevados a cabo por entusiastas del manga, quienes no solo llevan a cabo todas estas labores de forma paralela a la legalidad, sino que lo hacen sin una remuneración económica: «la noción original de la contra-cultura como el sello de movimientos subalternos que parecían codificados en su idealización como movimientos marginales (y en consecuencia) criminales». ${ }^{14}$

Bajo estas nociones, las scanlation no pueden estar dentro de la mezcla de medios real de la cadena de producción de manga pero sí tienen un efecto visible en el acceso de la audiencia, ya que es a través de esta práctica como llegan los productos a idiomas y regiones donde aún no lo ha logrado la máquina de producción institucionalizada. Dedicamos este espacio a la consideración y exposición del fan sub y la scanlation del anime y manga más allá de la discusión legal y económica de esta práctica, como forma de enmarcar también el consumo de productos por-

${ }^{13}$ Douglass, J., Huber, W. y Manovich, L. «Understanding scanlation: how to read one million fan-translated manga pages», en Image Eं Narrative vol. 12, n. 1 1, p. 4 (2011). Disponible en http:// manovich.net/index.php/projects/understanding-scanlation

${ }^{14}$ Bogarín, M. J. Op. cit. (2008) 
nográficos cuya distribución particularmente se ve diezmada en regiones fuera de Japón debido a las condiciones legales de la pornografía en estos otros lugares, por lo que depende mayormente, entonces, de estas prácticas para alcanzar nuevas audiencias.

Adicionalmente, nos ayuda a enmarcar también la construcción y perpetuación del discurso normativo en torno a la configuración del consumo del cuerpo y la mirada erótica, pues los canales oficiales de distribución de estas características eróticas están ceñidas a mercados pequeños donde: «only a small percentaje of Japanese titles are officially translated into English, mostly shonen titles marketed to young boys. Even these titles may see delays of months or years between the original and the translation release». ${ }^{15}$ Así pues, el fan service y el entorno de producción erótica en general está pensado para una mirada normativa que es definida por la mirada heterosexual del varón, dejando las otras identidades y formas de deleite, periféricas a la expansión multimodal.

\section{Pornografía y erotismo en Japón: del shunga al hentai}

El fan service de carácter erótico puede encontrarse en todos los géneros en los que se divide el manga, aun cuando existe un género dedicado a la narrativa erótica y las diferentes «perversiones» sexuales. Por lo tanto, es importante hacer la diferenciación entre todas estas formas de representación de lo sexual, según sus elementos estructurales.

El término hentai es un término nativo del lenguaje japonés que se podría traducir textualmente como «perverso» o «anormal». Según McLelland, ${ }^{16}$ hentai deriva de un término psicológico más amplio, hentai seiyoku, el cual hace referencia a los deseos sexuales anormales de un individuo. Por supuesto, esta clasificación de lo que es un deseo sexual «anormal» es dependiente de lo «normativo». Tras la Segunda Guerra Mundial, el interés del lector japonés sobre estas hentai seiyoku llegó a un auge, y esta demanda logró generar la industria del hentai para consumo popular, más allá de los textos académicos. ${ }^{17}$ Por otra parte, el término ecchi (derivado de una contracción de hentai, la pronunciación literal de la letra «h» en japonés) hace referencia a la práctica sexual desmedida o inapropiada; es decir, narrativas lascivas donde existía cierto grado de obscenidad, pero no llegaba a representar perversiones sexuales que estuvieran fuera de la normalidad. Por lo tanto, el ecchi como género es más cercano a nuestro entendimiento occidental de la pornografía, mientras hentai estaría más alineado con la idea de los fetiches.

15 Douglass, J., Huber, W. y Manovich, L. Op. cit. p. 11.

${ }^{16}$ McLelland, M. Op. cit.

17 Idem. 
Habría que hacer, por supuesto, un breve recuento histórico sobre la gráfica pornográfica japonesa, ya que el hentai es en realidad una conceptualización moderna que parte de la amalgama de la tradición erótica japonesa y las ideas importadas de Occidente tras la apertura de Japón con la guerra. El erotismo y el placer sexual en Japón eran cotidianos durante la era Clásica, ya que sus prácticas religiosas y culturales incluían al sexo como una parte fundamental de las macronarrativas mitológicas desde deidades hasta leyendas heroicas, la práctica sexual era una constante en el arte y la cultura. ${ }^{18}$ Con la unificación de Japón a principios del siglo xvir y el cambio de centro del poder político de Kyoto a Tokio (en ese entonces, Edo) vino un cambio social que no solo generó nuevas clases sociales, sino también nuevos medios de producción cultural ${ }^{19}$ que incluirían nuevas dinámicas de la clase emergente (chonin bunka) y nuevos mecanismos tecnológicos, como la impresión y grabado a través de planchas de madera.

Nacería en un periodo de menos de un siglo el shunga: representaciones visuales de arte japonés cuyo tema principal era el sexo. Estas producciones se acentuarían en el shogunato del periodo Edo como representaciones eróticas de la cotidianidad sexual japonesa, a través de personajes como los casados, las prostitutas, jóvenes y actores kabuki en situaciones sexuales.

No obstante, con las prohibiciones surgidas en el periodo Edo, las ilustraciones shunga pasaron a ser bienes distribuidos de manera clandestina al ser contempladas en las regulaciones impuestas a la prostitución y la separación de los sexos en circunstancias que pudieran «acentuar la libido» de la población. ${ }^{20}$

Con la llegada de la era Meiji a Japón y la modernización de este, el mercado de las ilustraciones shunga comenzaría a disminuir, sin desaparecer, en parte por la importación de ideologías occidentales, entre ellas la religión, que generó la percepción de lo sexual desde el tabú y también medios de producción de más rápida reproducción como la fotografía, que podían usarse para la producción pornográfica y con los cuales el grabado tradicional no podía competir. ${ }^{21}$ Finalmente, la aparición de la prensa y las producciones de manga acapararían el mercado de la gráfica japonesa y el shunga sería reemplazado (o rediseñado) a través del hentai.

Serían entonces los mangas hentai y ecchi de los que devendría la gramática del fan service erótico contemporáneo. Esta gramática erótica configura la mirada normativa

18 Frédéric, L. Japan Encyclopedia. Harvard University Press, 2005.

19 Idem.

${ }^{20}$ Jones, S. (ed.). Imaging/Reading Eros. Proceeding for the conference. Sexuality and Edo Culture 17501850. Bloomington, Indiana University, 1995.

21 Idem. 
para el mercado actual de consumo que, a diferencia de los shunga que exploraban pluralidades sexuales que iban desde las relaciones heterosexuales hasta el uso de animales y seres fantásticos, se mantiene en línea bajo la presentación de la sexualidad explícita heterosexual como la norma, y recluye todas las demás manifestaciones, que no han desaparecido, en el terreno de las perversiones sexuales.

\section{La gramática del deseo}

El hentai como fuente del discurso erótico recurre constantemente a elementos propios del soft porn como el desnudo, la infantilización y el fetiche para estructurarse y crear así no solo narrativas que propicien la excitación sexual, sino que puedan incluso generar humor. ${ }^{22}$ La base operativa del fan service erótico depende primordialmente de un proceso de objetivación del sujeto; ${ }^{23}$ es decir, la cosificación del personaje que lo reduce al estatus de un bien de consumo, más que una persona (o personaje). Esta objetivación del personaje se estructura principalmente bajo estos elementos dentro de la genealogía gramatical:

\section{El desnudo}

Ya sea como elemento cómico o de carácter sexual, el uso del desnudo total o parcial es un recurso común en el fan service, el cual se vale de contraponer la significación de la «privacidad» para sobajar al personaje, colocándolo en una desventaja ante la mirada omnipresente del espectador, generando así una relación de dominación entre la audiencia y el personaje. El recurso del desnudo recurre a mostrar el cuerpo hipersexuado de los personajes o prendas íntimas de ropa mayormente de forma injustificada en el relato. Según Kincaid, ${ }^{24}$ el desnudo del fan service, a diferencia del desnudo artístico, se ha transformado en una plataforma de soft porn que incluso ha reconfigurado la forma en que se presenta visualmente la pornografía en la cultura moderna.

En el caso de Japón, el desnudo solo tiene representación dentro de la acción gráfica que le dé un propósito: el baño, el sexo, el vestirse, etc. La configuración de este elemento en el manga respondería mayormente a una representación aparentemente incidental, dentro del marco de una acción específica, y busca normalmente tres reacciones afectivas: el humor, el sentimentalismo o la excitación sexual. ${ }^{25}$

\footnotetext{
$\overline{22}$ Kincaid, C. Op. cit.

${ }^{23}$ Idem.

24 Idem.

25 Idem.
} 
Si la desnudez es fundamental en la construcción visual del fan service, este responde mayoritariamente al erotismo dirigido al público masculino, donde el cuerpo de la mujer es el más representado dentro de la construcción erótica: grandes bustos, faldas cortas y posiciones sugerentes son en realidad una notable mayoría que además cubre todo el espectro de reacciones afectivas mencionadas anteriormente, a diferencia del uso erótico del cuerpo masculino, que comúnmente se utiliza como un recurso cómico dentro del manga tradicional. El desnudo será quizá la base casi indispensable de todo fan service erótico que puede combinarse con otras formas de sexualización, lo que genera, así, una forma de ver y consumir el cuerpo, la cual responde mayormente a una mirada heteronormativa. ${ }^{26}$

Podemos contrastar este elemento en el hentai moderno con los motivos visuales comunes en el shunga tradicional como una forma de, quizá, "proto hentai» para poder acentuar la diferencia de elementos y así hacer una mejor delimitación de los elementos tradicionales. En las ilustraciones shunga el desnudo parcial o total es una constante como forma de erotización del cuerpo. La representación del cuerpo y los genitales se acentuaba, sobre todo tras la separación de los baños comunitarios por sexos, donde ahora el cuerpo del otro ya no estaba al alcance.

Como una extensión del desnudo como elemento gramatical del deseo en el fan service tenemos también el deleite voyerista. Esta acción configura el cuerpo del otro como un fetiche y abona a la construcción de la relación de dominación entre los personajes y la audiencia, donde ahora un segundo personaje se introduce como elemento vicario al consumo del cuerpo del otro, ya sea para fines cómicos o puramente eróticos.

\section{La infantilización del personaje}

El modelo «Lolita» para la concepción occidental: este recurso se estructura ante la oposición de la vulnerabilidad y la hipersexualidad en un mismo signo. La cultura visual lolikon es la representación de la mujer como niña frágil, sumisa y vulnerable para mostrarla como tierna y a la vez hipersexuada y deseable, a manera de «instrumentalización de la mujer para perpetuar su sumisión». ${ }^{27}$ La representación del lolikon (y el shotakon, su versión masculina) es común en el hentai bajo el fetiche de la sexualidad infantil latente. Se consideran los motivos visuales del lolikon como elementos esenciales dentro de la cultura de consumo otaku.

Vale aclarar que la relación conceptual entre estos motivos visuales con la novela de Nabokov es una traducción problemática. En la novela de Nabokov, Dolores es una chica con intereses de su edad y Humbert es un hombre maduro con poco o nulo

\footnotetext{
${ }^{26}$ Hemmann, K. Op. cit.

27 Bogarín, M. J. Op cit. (2009).
} 
interés en la cultura de la joven, sino el fetiche de su atractivo físico. En la concepción del lolikon como cultura de consumo, las chicas son representadas bajo una apariencia infantil pero con personalidad activa, sexualizadas debido a la presentación de los elementos de la feminidad tradicional de las mujeres jóvenes, pero cuya carga erótica nace en la visión masculina de la audiencia que lo consume con activo interés en esta cultura shojo. ${ }^{28}$ Dentro del marco de la construcción de una gramática del erotismo, el modelo lolikon se reduce en realidad a los puros motivos visuales que relacionan simbólicamente al objeto de deseo con los recursos estéticos del lolikon: el uso de uniformes escolares, la apariencia tierna y vulnerable, la relación (perversa) de poderes entre el hermano mayor y la hermana menor, etc. Estos elementos si bien provienen de una cultura moderna, lanzada por la mujer joven en Japón en los años finales del siglo xx, donde se vería a la edad escolar de la mujer como sus «años libres» ante la obligación social de convertirse en amas de casa terminados los estudios, ${ }^{29}$ tienen poca relación con el espacio político generado por el shöjo, salvo el uso de motivos visuales como fuente de erotismo que puede cargarse también a otros seres «inhumanos» que se cosifican y erotizan a través de la imposición visual de los modelos lolikon.

El recurso de infantilización también abona a la creación de un sometimiento del otro a través de la mirada, donde el ojo del espectador actúa como un agente de dominación que destruye y pervierte las nociones preconcebidas de la inocencia infantil, ${ }^{30}$ para generar así una configuración del cuerpo hipersexuado del «infante» a través del fetiche. ${ }^{31}$ Este recurso es uno de los más utilizados en la producción erótica de fans, normalmente utilizando personajes existentes cuya esencia se alinea con la inocencia infantil o una condición del personaje en el producto original, para volcarse sobre la hipersexualización dentro de la producción no oficial.

Habría que considerar además que la estética del lolikon es en realidad una perversión hipersexualizada de la estética shōjo tradicional nacida de la cultura gráfica de novelas y revistas para mujeres jóvenes, cuyos motivos visuales nacen con Makoto Takahashi, ${ }^{32}$ pero ahora han sido institucionalizados en claustros de mujeres artistas

${ }^{28}$ Hinton, P. «The Cultural and the Interpretation of Japanese "Lolita Complex"», en Style Anime. Intercultural Conunication Studies, xxıII, n. 2 (2014), p. 61. Disponible en https://web.uri.edu/iaics/ files/Perry-R.-Hinton.pdf

29 Allison, A. Permitted and Prohibited Desires: Mothers, Comics, and Censorship in Japan. California, University of California Press, 2000, p. 14.

${ }^{30}$ Boyd, D. «"Nonsensical is our thing!": Queering fanservice as "Deleuzional” desire-production in Studio Trigger's Kiru ra Kiru / Kill La Kill», en Queer Studies in media E popular culture vol. 1, n. ${ }^{\circ}$ 1, pp. 61-83 (2016).

31 Hinton, P. Op. cit., p. 53.

32 Castellanos, A. «Mujeres mágicas de ayer y hoy: una comparativa de Sailor Moon con el discurso del s. XIX», en $\operatorname{Argus}-A$ vol. VII, edición n. ${ }^{\circ} 28$ (junio de 2018), pp. 1-16. Disponible en http://www. argus-a.com.ar/publicacion/1340-mujeres-magicas-de-ayer-y-hoy-una-comparativa-de-sailormoon-con-el-discurso-del-s-xix.html 
que definen el shōjo bunka como una forma de generar identidad propia a través de la estética y los discursos políticos de liberación femenina. Una comparativa visual entre la identidad gráfica del shōjo bunka y la estética lolikon sexuada nos pone en evidencia la sexualización de la inocencia idílica femenina como acto de consumo de la mujer, su sexualidad y su cultura a través de una mirada masculina normativa.

La infantilización del personaje como motor del deseo y la estética lolikon son importantes mecanismos de producción cultural para la mirada heteronormativa masculina en el fan service, ya que crean un elemento gramatical que configura el cuerpo femenino como la fuente principal del consumo erótico. Incluso en su versión masculina, el shotacon, este recurso de infantilización sigue respondiendo ampliamente a una normativa heterosexual donde los personajes infantilizados y sexuados masculinos se configuran desde las funciones normativas del performance femenino vistas desde la hegemonía heterosexual.

\section{El fetiche y exageración de los roles binarios de género}

En las producciones hentai, los personajes satisfacen funciones normativas de los roles de género dentro de la narrativa sexual. Estas sexualidades se configuran por supuesto bajo la mirada del sexo heterosexual idealizado en donde el hombre desempeña el rol sexual activo de dominación mientras la mujer adopta el rol pasivo de sumisión. Curiosamente, en la gráfica japonesa tradicional shunga, la representación sexual carecía de estos tonos de dominación y la mujer realmente no era mostrada como sometida o pasiva, así como el hombre no representaba un agente físicamente dominante..$^{33}$ Es decir: el shunga planteaba la representación del sexo desde la mirada erótica placentera que mostrara la cotidianidad sexual para deleite por igual de hombres y mujeres.

En la estética normativa del hentai, las relaciones sexuales son vistas a través de una relación de dominación de un personaje sobre el otro, regularmente del hombre a la mujer, donde el placer sexual del sumiso está supeditado al propio placer del observador, quien encuentra el deleite en la sumisión del personaje y su aparente goce debido a esta dominación sexual; incluso en textos donde la mujer aparentaría tener un rol jerárquico (la hermana mayor, la figura materna, la jefa laboral, la profesora, etc.) la dominación deviene inevitable al construir los momentos sexuales. Esta gramática es común incluso en los mangas con parejas gays que inicialmente se contemplaban dentro del espectro hentai, al ser vistas estas sexualidades como «fuera de la norma» ${ }^{34}$ y que serían, a una primera vista, las opciones «alternativas» a la sexualidad configura-

\footnotetext{
${ }^{33}$ Miller, L. Beauty up: Exploring Contemporary Japanese Body Aesthetics. California, University of California Press, 2006.

${ }^{34}$ McLelland, M. Op. cit.
} 
da bajo la heteronormativa. Aquí sin embargo en la práctica cotidiana, se impone y se exageran los roles binarios de género en las relaciones sentimentales y eróticas, sean estas heterosexuales u homosexuales bajo el crisol normativo.

Este recurso propone la construcción del erotismo o el romance desde la dicotomía de tener un personaje dominante (el seme) y un personaje sumiso (el $u k e$ ) que representen las visiones simplistas y normativas de lo masculino y lo femenino. ${ }^{35}$ Este elemento se estructura a través de la politización y reducción de lo sexual a quien «penetra» y quien «es penetrado» en una relación, llevando dicha función fisiológica del cuerpo a una representación cultural del personaje que, al acentuarlo, intensifica el erotismo sexual en la relación al convertir ambas funciones en objetos de consumo.

Por supuesto, estos elementos centrales sobre los que se estructura el fan service erótico en el manga siguen respondiendo a una construcción de la mirada masculina heteronormativa ${ }^{36}$ pues es esta la que sigue representando el discurso dominante, acaparando así la producción de motivos visuales eróticos como la norma a seguir. Incluso las producciones yaoi, si bien transgresoras de la sexualidad normativa, utilizan esta gramática, definiendo los roles protagónicos aún desde una binaria sexual normativa de las funciones femeninas y masculinas. A consecuencia de esto, han surgido otras producciones que buscan romper con la mirada masculina heteronormativa, para producir otras políticas de representación subversivas, estructurando el erotismo desde una mirada queer. ¿Cómo se estructuran estas narrativas visuales para mover el punto de enunciación y de vista fuera de la normativa? Es a través del uso y reestructuración de esta misma gramática con la que se logra dicho emplazamiento.

\section{La mirada queer, el fan service subversivo en el yaoi}

Aunque existen representaciones subversivas de la sexualidad y diferentes puntos de enunciación queer en la corriente principal del manga, es realmente en las producciones hechas por la audiencia, quien ahora es lector y autor a la vez, donde existe una visible proliferación de representaciones fuera de la norma.

Es importante aclarar que en Japón la producción tradicional de cómic y la producción casera del fandom (el doujinshi) no están tan separadas como lo estarían la producción tradicional y la que carece de licencia en nuestra estructura económica occidental: «instead of discouraging fan works such as fan fictions, fan art and fan comics, Japanese media producers depend on them to ensure a healthy and stable

\footnotetext{
35 Hemmann, K. Op. cit.

${ }^{36}$ Kincaid, C. Op. cit.
} 
economic ecosystem for their franchise property». ${ }^{37}$ Por lo tanto, las producciones fan made of recen un valor significativo para el medio, tanto por su fuerza discursiva como por su peso económico.

Un importante sector de las producciones de doujinshi es la de género yaoi: historias románticas y/o sexuales con protagonistas hombres (BL, Boy Love, es el término coloquial) comúnmente tomados de otras historias existentes o con personajes originales. Este género es especialmente popular entre las mujeres ${ }^{38}$ quienes son las principales lectoras y productoras de estas historias, generando incluso un claustro cultural conocido como Fujoshi. ¿En qué parte de este sistema de producción se genera la representación de la sexualidad subversiva, más allá del evidente uso de la homosexualidad masculina como excusa del relato? La respuesta recae en la forma de apropiación de estas producciones y su valor simbólico no en la sexualidad representada, sino en lo que aporta a la propia del lector. Según Alexandra Chocontá, quien haría en 2014 un estudio cualitativo sobre la relación de la voz del deseo en el manga yaoi:

La juventud es para las mujeres una etapa en la que se presenta una forma particularmente represiva de la sexualidad pues [...] comienza a ser configurada a través de regulaciones morales, económicas y religiosas que se implantan en sus cuerpos y restringen el grado de autonomía que pueden poseer sobre sí mismas. ${ }^{39}$

¿Sería entonces el manga yaoi una plataforma para que las mujeres jóvenes puedan lidiar con estas configuraciones de su propia sexualidad, impuestas por la norma? Estas historias politizan la representación masculina, insertándola dentro de estas configuraciones normativas; es decir, la exploración de la propia sexualidad masculina se ve a través de la matriz que la normativa impone a la mujer y se cosifica al hombre, bajo la excusa del sentimentalismo romántico, de la misma forma que la mirada masculina lo hace con la mujer.

Con esto, se ajusta la fórmula de la sexualidad normativa y se presenta no solo una visión evidente de la homosexualidad (que por sí misma es una alienación a la norma heterocentrista), sino que además impone las mismas regulaciones sexuales sobre estos hombres desde un nuevo punto de enunciación pero siguiendo de forma irónica la norma: una pareja compuesta de la función masculina exagerada del seme (el hombre alto, serio, fuerte y varonil) en conjunto con la función femenina caricaturizada del uke (el hombre bello, sensible, vulnerable y delicado) creando una mirada queer dentro

37 Hemmann, K. Op. cit.

38 Chocontá, A. «Manga yaoi y Fujoshis: Exploración de la propia voz del deseo como alternativa al gobierno de la sexualidad juvenil», en Universitas Humanistica n. ${ }^{\circ} 79$ (enero-junio de 2015), p. 226. Disponible en http://www.redalyc.org/articulo.oa? id=79132009010

${ }^{39}$ Ibid., p. 216. 
de la fórmula dominante, demostrando así la fragilidad de su sistema a la vez que pone en evidencia las imposiciones sexuales hechas sobre la mujer.

Según Hemmann, la producción yaoi por las fans mujeres del manga erótico pueden ser espacios artísticos para una importante manifestación política donde las autoras pueden deconstruir la imagen gastada de la feminidad normativa y explorar la sexualidad masculina y andrógina haciendo una crítica sobre las imposiciones hechas a la sexualidad femenina por la hegemonía. Así, el doujinshi yaoi es una construcción discursiva que «subvert the original text by challengin and queering phallocentrism». ${ }^{40}$

Estas nuevas producciones que se muestran periféricas a la gramática normativa del deleite crean entonces una mirada queer del placer sexual; es decir, nuevas enunciaciones del deleite que ya no dependen o responden a la configuración antes explorada de los elementos eróticos heterocentristas.

Estas producciones subversivas, si bien son más comunes en la producción hecha por fans, también existen en los mercados institucionalizados contemporáneos con el mismo valor discursivo, ya que abordan, cuestionan, discuten y desmontan las macronarrativas hegemónicas del deleite.

\section{Magical girls: el escenario ideal para la mirada queer al placer}

El género de las magical girls surge a mediados del siglo xx, como una nueva ola del shöjo manga donde se presentaba a la mujer desde una perspectiva fantástica como heroína, y no solo como objeto de deseo. Se considera que Mahotsukai Sally es el producto que originó la corriente de magical girls y sería casi cincuenta años después que Sailor Moon de Naoko Takeuchi oficializaría los tropos, ya independiente del shōjo. ${ }^{41}$ Como herencia del shōjo bunka, este nuevo género utilizaría los motivos visuales del shöjo para reformular un discurso de empoderamiento femenino a través de replantear la representación femenina desde el ejercicio soberano de la propia identidad sexual como analogía del poder mágico. ${ }^{42}$

Esta premisa de la liberación sexual femenina a través del arte en el shōjo bunka no es exclusiva del género de las magical girls. El mismo shöjo bunka se ha convertido con los años en un claustro cultural para la generación de contenido enfocado en la

$\overline{40}$ Hemmann, K. Op. cit.

${ }^{41}$ Castellanos, A. Op.cit.

${ }^{42}$ Russell, N. «Make-Up: The Mythic Narrative and Transformation as a Mechanism for Personal and Spiritual Growth in Magical Girls (Mahō Shōjo) Anime». [Trabajo de Máster], University of Victoria, Master of Arts, 2017. Disponible en https://dspace.library.uvic.ca/bitstream/handle/1828/8496/russell ndonna MA 2017.pdP?sequence=18isAllowed=y 
representación de la feminidad contemporánea; ${ }^{43}$ sin embargo, en las magical girls el discurso sobre el cuerpo se mantiene más o menos constante donde la expresión de la sexualidad femenina, como identidad o performativa, es la fuente metafórica del despertar del poder femenino, ya que es un «acto de subversión a las reglas patriarcales $[\ldots]$ que plantea redefinir la construcción idílica de la mujer [...] por una nueva idea en que la mujer puede alcanzar esta nueva identidad ideal a través de tomar control de su propia sexualidad», ${ }^{44}$ ya sea esto para generar un discurso feminista de emancipación o como crítica y deconstrucción de la idea de un supuesto empoderamiento.

Aplicaremos lo analizado anteriormente sobre la gramática del deleite erótico a productos postmodernos del género magical girls, específicamente a productos con un tono subversivo con discursos más transgresores. Los productos de magical girls que revisaremos presentan esta enunciación queer al placer erótico, tomando la gramática normativa con nuevos emplazamiento para configurar una mirada subversiva:

Kill La Kill de Kazuki Nakashima, para ilustrar el uso del cuerpo erotizado y la crítica a la sexualización de la mujer con un contradiscurso que reta la normativa heterosexual.

Mahō Shöjo Ore de Icchokusen Mokon, para ilustrar la deconstrucción a través de la parodia de los elementos gramaticales del deleite erótico cambiando el punto de emplazamiento en la configuración de la mirada del consumo.

Cute Earth Defense Club LOVE de Takahashi Natsuko, como parodia del género bajo la construcción del maho shonen (magical boy) donde revisaremos la queerificación de la performatividad masculina y el consumo del cuerpo desnudo bajo los motivos visuales impuestos al cuerpo femenino en el género tradicional.

\section{Kill La Kill: del vestir y el nudismo}

Kill La Kill es la historia de Ryuko Matoi, nueva estudiante de la academia Honnoji que busca vengar la muerte de su padre. La academia Honnoji está dominada por la presidenta del consejo estudiantil, Satsuki Kiryuin, quien gobierna de forma fascista no solo la academia, sino también la ciudad donde se encuentra. Algunos estudiantes de Honnoji portan uniformes con «fibras vivas» las cuales les dan poderes especiales que se clasifican según el rango de poder desde una hasta cuatro estrellas. Estos trajes son fabricados por el club de costura de la academia, bajo el control de Satsuki, quien determina a quién y cómo se le otorgará el poder de uno de estos poderosos

\footnotetext{
${ }^{43}$ Takahashi, M. «Opening the Closed World of Shojo Manga», en MacWilliams, M. W. Japanese Visual Culture: explorations in the world of manga an anime. Routledge, 2008, pp. 114-136.

${ }^{44}$ Castellanos, A. Op. cit.
} 
uniformes. Matoi encontrará a Senketsu, un traje mágico especial que le dará increíbles poderes para poder derrocar el fascismo de Satsuki y vengar la muerte de su padre.

Kill La Kill presenta en primera instancia uno de los tropos más comunes en el género: la transformación mágica de la mujer al momento de despertar los poderes mágicos que usará para combatir a sus enemigos. En un paralelismo a la clásica secuencia de transformación en Sailor Moon, Matoi adquiere poderes insuperables gracias a su unión simbiótica con Senketsu, el traje de batalla, en Kill La Kill «fashion literally translates to physical power [...]. It is also associated with politica power». ${ }^{45} \mathrm{El}$ traje de batalla de Matoi en Kill La Kill tiene vagas similitudes con los trajes de las chicas en Sailor Moon pero opera bajo una función similar: sexualizar el cuerpo femenino como metáfora del despertar sexual de la mujer que se convierte en la base discursiva para el empoderamiento femenino en el anime y manga. ${ }^{46}$

Lo que hace Kill La Kill es tomar el discurso tradicional donde la ropa y los artilugios mágicos son la manifestación del poder femenino y las ansiedades patriarcales ante la subversión del género dentro de la estructura de dominación, ${ }^{47}$ pero genera una correlación entre el ejercicio del poder y la hipersexualización femenina de consumo; es decir, la adquisición del poder para el agente femenino requiere en compensación patriarcal ante esta transgresión la exposición del cuerpo como objeto de consumo para el observador, principalmente masculino y heterosexual. Con este acto, Kill La Kill cuestiona los productos tradicionales del género al poner en evidencia cómo el glamour del poder femenino a través de la codificación de la estética kawaii aún representa un sometimiento a la mirada lasciva heteronormativa donde el cuerpo de la mujer aún se configura como objeto de consumo, independientemente del rol protagónico o «empoderado» de la mujer.

Al final de la historia de Kill La Kill, Matoi descubre que la única forma de acceder a todo el potencial de su poder es a través de la exposición voluntaria de su cuerpo y que es justo abrazando el exhibicionismo que deviene de su transformación y también su propio cuerpo desnudo que tanto rechaza como podrá vencer a la tiranía. Este discurso se topa con la inclusión de un elemento importante que rompe la visión heteronormativa en la serie: el amor yuri entre Matoi y Mako.

Kill La Kill construye constantemente la sexualización del cuerpo femenino solo para arrancarlo al final a la mirada heteronormativa y emplazarla desde una perspectiva queer donde Mako, la contraparte amorosa de Matoi, es presentada sin sexualización ni exposición del cuerpo de consumo, sino como un agente que interrumpe y

\footnotetext{
45 Boyd, D. Op. cit., p. 64.

46 Russell, N. Op. cit.

47 Boyd, D. Op. cit., p. 74.
} 
trasgrede los momentos de deleite erótico con performatividad queer que: «violently undercuts the logic of heteronormativity that urges toward a conjunctive synthesis of capital (commodity) and subjectivity (otaku) in a queer context». ${ }^{48}$ Kill La Kill entonces quita el centro de la mirada en la lógica normativa para presentar una nueva configuración de deseo que se antoja para consumo de otras identidades periféricas que niegan las condiciones binarias del género.

A la par de la exhibición del cuerpo de Matoi para consumo, la serie está llena de muestras de desnudo de todo tipo y en personajes de ambos sexos. Si bien Matoi funciona al principio quizá como una «carnada» para la mirada normativa para el consumo erótico, obliga a este espectador que consume desde esta enunciación política a consumir también el cuerpo masculino en constante exposición sexualizada tanto performativa como con desnudos explícitos y a la par de una castración simbólica ${ }^{49}$ que obliga al espectador a experimentar la incomodidad de estar expuesto y ser cosificado de regreso, al forzarlo a consumir el deleite que no buscaría por sí mismo.

\section{Mahō Shōjo Ore: hentai y consumo del cuerpo desde la mirada queer}

Mahō Shöjo Ore, por su condición de parodia, aborda a través del humor los mecanismos reales que enmarcan el proceso de producción del manga, las convenciones usuales del género de magical girls y la gramática del fan service. A grandes rasgos, Mahō Shöjo Ore es la historia de Saki Uno, una chica que se topa con el inesperado destino de convertirse en una chica mágica en un universo donde estas son muy poco ortodoxas: su forma mágica es la de hombres musculosos con notorios atributos sexuales pero en trajes de combate que siguen dentro de la estética kawaii tradicional de los motivos visuales shöjo.

Este manga ofrece numerosas escenas de fan service erótico de carácter subversivo, ya que buscan alterar el punto de enunciación con el que se construye el erotismo, comúnmente heteronormativo, para generar una mirada queer de la sexualidad, reacomodando la gramática visual de esta. Mahō Shōjo Ore borra las líneas que dividen el hentai, el ecchi y el fan service, recurriendo a las convenciones del desnudo y la hipersexualización del cuerpo, en un catálogo amplio de «perversiones sexuales» dignas del término hentai.

Mahō Shöjo Ore busca la queerificación de la mirada del deleite al mantener aparentemente intactos todos los elementos de la gramática erótica revisados anteriormente, incluso bajo la pretensión de aplicarlos también al consumo del cuerpo femenino,

\footnotetext{
48 Idem.

49 Idem.
} 
solo para cambiar el foco de esta mirada de consumo y forzar la cosificación al cuerpo masculino desde una sexualización poco convencional que mantiene los elementos de lo normativo sexual femenino, el mismo sometimiento pasivo, en un cuerpo visiblemente erotizado en el hombre.

El emplazamiento de las representaciones en una perspectiva queer puede notarse cuando el personaje de Saki debe enfrentarse a un monstruo poco común. Rápidamente la escena deviene en la gramática común del hentai como sometimiento del agente sexual por tentáculos, un motivo visual pornográfico repetitivo en la ilustración japonesa que funciona como metáfora del sometimiento sexual, «usually applied to solitary girls and women who are openly exposed to the gaze of the reader, not to men who are shielded from the reader's gaze». ${ }^{50}$

$\mathrm{El}$ autor nos muestra en la portada la fórmula normativa de hentai enunciado desde la mirada masculina normada, cumpliendo con la gramática visual que logra sobajar y cosificar al personaje femenino al colocarlo en posiciones hipersexuales, sometida e indefensa ante el consumo de la mirada del espectador. Dentro del volumen, el autor repite esta misma escena, siguiendo exactamente la misma gramática, pero ahora, en lugar de un personaje femenino, tenemos un personaje masculino de carácter dominante, el seme del yaoi, quien es ahora dominado y cosificado, indefenso ante el consumo de la mirada del espectador.

Es aquí donde el autor obliga al lector a adoptar una postura queer desde su condición de espectador, forzando esta mirada política en él sin importar sus condiciones personales. Al construir el mismo mito de la escena, emulando los elementos de la representación tradicional, el autor logra forzar al consumidor a ver desde la perspectiva queer toda la construcción del erotismo visual: se sigue dominando y poseyendo al personaje, quien sigue en un atuendo a lo lolikon y que se presenta todavía en posturas sexuales sugestivas, pero ahora la imagen no es una mujer atractiva, sino un hombre sexualmente acentuado y cuya performatividad de género se alinea con lo masculino heteronormado: la caricatura del hombre heterosexual idealizado que define la mirada normativa.

Esta representación, tan política como erótica, es una metáfora de la misma dominación, de forma que las páginas son el equivalente a los tentáculos que aprisionan y obligan al espectador a mirar de una manera en que usualmente no lo hace, y a consumir ahora a quien siempre ha sido el consumidor, como si el autor intentara invertir los papeles y convertir al dominante en dominado, forzando este punto de enunciación como afirmación política contra la matriz binaria del sexo que, al politizarse, plantea definir el género y la sexualidad bajo esa misma estructura determinista. Aun así, al hacer una revisión histórica de la gráfica erótica japonesa, el uso de estas

$\overline{{ }^{50} \text { Hemmann, K. Op. }}$. cit. 
ataduras y sometimiento existen desde los shunga tradicionales, aunque sin el verdadero discurso de sometimiento femenino. Por el contrario, el sentido discursivo era el de generar parodias de la sexualidad cotidiana y los deseos perversos (hentai en el sentido más literal) del espectador.

Mahō Shöjo Ore es una denuncia de la sobreexplotación del cuerpo femenino ante la mirada erótica de consumo y una deconstrucción que pone en evidencia los elementos gramaticales de los que hemos hablado anteriormente, pero aplicados solo al cuerpo de la mujer para deleite de la mirada heteronormativa. Así, Ore obliga al espectador a experimentar una mirada erótica desde una enunciación diferente, que excita tanto como perturba, ya que diseña las nuevas directrices de la mirada queer dentro del consumo erótico.

\section{Cute Earth Defense Club Love: la performatividad masculina periférica}

La construcción de la mirada queer en el anime puede recurrir a otras formas de fan service quizá menos sexualizadas pero aún con una carga de erotismo que alcance a politizar el cuerpo con la mirada, buscando un discurso que desafíe la mirada normada, donde lejos de explorar la sexualidad explícita del hentai, se presentan nuevas formas de entender la masculinidad performativa y de mirar el cuerpo masculino.

CHEDCL es una parodia del género de magical girls donde los héroes son hombres, y que hace una caricatura de las secuencias mágicas de transformación, tropo común en el género de magical girls, comúnmente una metáfora del despertar sexual de la mujer joven en desarrollo. ${ }^{51}$ CHEDCL exhibe de forma irónica el cuerpo masculino desnudo para deleite del espectador, pero insertándolo en la estética feminizada y kawaii que es normalmente impuesta sobre las chicas en el género para hablar también de una erotización de la figura del hombre, mostrando sin embargo una performatividad queer que se contrapone al actuar usualmente heteronormado de la mayoría de los protagonistas del relato.

CHEDCL intenta mostrar una mirada queer no solo en la politización de la mirada erótica del cuerpo masculino, sino también en la presentación de diferentes formas de masculinidad fuera de lo que Butler llamaría «la lógica del binarismo de género». CHEDCL pone en evidencia no solo el espectro plural de performatividades masculinas en un nivel subversivo evidente, sino también los roles estereotípicos que se han impuesto a los personajes femeninos a lo largo de la historia cultural del Japón postmoderno (o, nuevamente en términos de Butler, la «normativa del imperialismo heterosexual masculino»).

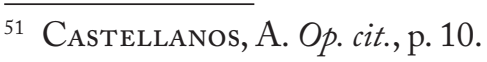


CHEDCL invierte activamente las reglas de la representación binaria del género y su uso como fetiche. Este anime expande las reglas del género magical girls y su metáfora mágica como una forma de poder subversivo a la hegemonía falocentrista y la aplica a los hombres cuya performatividad no está, precisamente, dentro del espectro normativo de la masculinidad. Entonces, para los chicos mágicos del relato, la transformación mágica es también una forma de trasgredir las reglas sociales que configuran el cuerpo masculino a través de las estructuras de poder mencionadas por Foucault, en un discurso aplicable a la erotización tradicional que opera bajo la mirada normativa: el desnudo del cuerpo masculino puede ser más que un elemento de comedia o una muletilla fragmentada para completar el acto sexual donde se explota lo femenino, sino que puede ser también objeto de consumo en sí mismo, dentro de la producción erótica para miradas periféricas.

\section{Conclusiones}

El término hentai se relaciona lingüísticamente con el término queer ya que su connotación en ambos idiomas sería similar; sin embargo, mientras en Occidente el término queer es más bien transgresor y ofensivo, el término hentai en Japón es más bien descriptivo. ${ }^{52}$ No es sorpresa entonces que la producción hentai sea una plataforma fértil para la representación de perspectivas queer que aborden performatividades subversivas. Elementos visuales como el fan service, si bien pueden parecernos descarados por su uso en la producción económica del medio, se han vuelto motivos visuales ya normalizados en la gramática del cómic japonés que pueden usarse como bloques en la construcción del humor y el discurso, más allá de su pura naturaleza económica.

Las representaciones queer contemporáneas, tanto en la producción tradicional como fan made, son esenciales para contribuir a un espectro cultural más amplio en cuanto a representaciones políticas dentro de la novela gráfica y animación, apelando a la naturaleza plural del lector, entendido como colectivo, quien exige cada vez más intensamente estas representaciones en sus productos de consumo. Así los autores de estos productos subversivos utilizan la gramática que estructura el deseo y la producción erótica en el manga para denunciar la naturaleza heteronormativa del grueso de las producciones eróticas, tanto las hechas por fans como las institucionalizadas, y crean así nuevos discursos que se recarguen en la representación plural del cuerpo y las relaciones eróticas entre el espectador y el contenido de los productos culturales.

$\overline{52}$ McLelland, M. Op. cit., p. 2. 


\section{BibLIOGRAFÍA}

Aluison, A. Permitted and Prohibited Desires: Mothers, Comics, and Censorship in Japan. California, University of California Press, 2000.

Bogarín, M.J. «El sustrato teórico del fenómeno otaku», en Revista Observaciones Filosóficas, n. ${ }^{\circ} 6$ (2008). Disponible en https://www.observacionesfilosoficas.net/ elsustratoteorico.html

— «Kawaii y la cosificación de la mujer en el manga-anime», en Escaner cultural (1 de febrero de 2009). Disponible en http://revista.escaner.cl/node/1157

BoyD, D. «"Nonsensical is our thing!": Queering fanservice as "Deleuzional" desire-production in Studio Trigger's Kiru ra Kiru / Kill La Kill», en Queer Studies in media E' popular culture vol. 1, n. ${ }^{\circ}$ 1, pp. 61-83 (2016).

Butler, J. Lenguaje, poder e identidad. Madrid, Síntesis, 2009.

Castellanos, A. «Mujeres mágicas de ayer y hoy: una comparativa de Sailor Moon

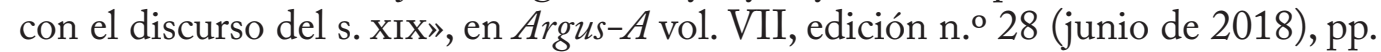
1-16. Disponible en http://www.argus-a.com.ar/publicacion/1340-mujeres-magicas-de-ayer-y-hoy-una-comparativa-de-sailor-moon-con-el-discurso-del-s-xix. $\underline{\mathrm{html}}$

ChocontÁ, A. «Manga yaoi y Fujoshis: Exploración de la propia voz del deseo como alternativa al gobierno de la sexualidad juvenil», en Universitas Humanistica n. 79 (enero-junio de 2015), pp. 211-229. Disponible en http://www.redalyc.org/ articulo.oa?id $=79132009010$

Claretie, J. L'Art Francaise, en L'art et les Artist Francais, Ed. BilboBazaar (1872).

Deuce, M. y Jenkins, H. «Editorial. Convergence Culture», en The International Journal of Research into New Media Technologies, vol. 14 (1) (2008), pp. 5-12. Disponible en https://journals.sagepub.com/doi/pdf/10.1177/1354856507084415

Douglass, J., Huber, W. y Manovich, L. «Understanding scanlation: how to read one million fan-translated manga pages», en Image E Narrative vol. 12, n. ${ }^{\circ}$ 1 (2011). Disponible en http://manovich.net/index.php/projects/understanding-scanlation

FréDÉric, L. Japan Encyclopedia. Harvard University Press, 2005. 
Hemmann, K. "Queering the media mix: The female gaze in Japanese fan comics», en Transformative Works and Cultures, n. 20 (2015). Disponible en https://journal. transformativeworks.org/index.php/twc/article/download/628/540?inline=1

Hills, M. «Transcultural otaku: Japanese representations of fandom and representations of Japan in anime/manga fan cultures», (2002). Disponible en https:// pdfs.semanticscholar.org/d62f/f6eb6025b29ab22dddf60ee0bfbf5bea2bda.pdf? $\mathrm{ga}=2.38970211 .1583092000 .1572795111-98359923.1572795111$

Hinton, P. «The Cultural and the Interpretation of Japanese "Lolita Complex"», en Style Anime. Intercultural Conunication Studies, xxıII, n. 2 (2014), pp. 54-68. Disponible en https://web.uri.edu/iaics/files/Perry-R.-Hinton.pdf

Jones, S. (ed.). Imaging/Reading Eros. Proceeding for the conference. Sexuality and Edo Culture 1750-1850. Bloomington, Indiana University, 1995.

KIncaid, C. «Undressing anime fan service», en Japan Powered (1 de diciembre de 2008). Disponible en https://www.japanpowered.com/anime-articles/undres$\underline{\text { sing-anime-fan-service }}$

McLelland, M. «A Short History of 'Hentai'», en Intersections: Gender, History and Culture in the Asian Context n. 12 (enero de 2006). Disponible en http://intersections.anu.edu.au/issue $12 / \mathrm{mclelland.html}$

Miller, L. Beauty up: Exploring Contemporary Japanese Body Aesthetics. California, University of California Press, 2006.

Russell, N. «Make-Up: The Mythic Narrative and Transformation as a Mechanism for Personal and Spiritual Growth in Magical Girls (Mahō Shōjo) Anime». [Trabajo de Máster], University of Victoria, Master of Arts, 2017. Disponible en https://dspace.library.uvic.ca/bitstream/handle/1828/8496/russell ndonna MA 2017.pdf? sequence $=1$ \&is Allowed $=y$

Takahashi, M. «Opening the Closed World of Shojo Manga», en MacWILLIAMs, M. W. Japanese Visual Culture: explorations in the world of manga an anime. Routledge, 2008, pp. 114-136. 